\title{
Functional Design of Sonotrodes for Deep-drawing of Cardboard
}

\begin{abstract}
Albrecht Löwe, ${ }^{*}$ Anke Nikowski, and Marek Hauptmann
The functional design of ultrasonic sonotrodes for deep-drawing is considered. The achievable stability, shape deviation, and surface roughness of deep-drawn cups were determined as a function of the vibration mode, the vibration amplitude, and the contact pressure as it occurs in the gap between the tools. Because the development of sonotrodes is complex and expensive, substitute experiments were conducted that allowed the cup parameters to be determined even without the manufacture of numerous sonotrodes, thus minimizing the effort involved. The results showed that the vibration mode, which determines the angle at which the vibration hits the material surface, is the most important influencing factor. The best way to increase stability and reduce shape deviation and surface roughness is to use an oscillation that hits the material surface perpendicularly during the entire deep-drawing process. With perpendicular vibration, the strength of the cup wall increased up to $200 \%$ compared to the one produced without ultrasound. The surface roughness could be reduced to $50 \%$ with the vertical vibration compared to without ultrasonic support.
\end{abstract}

Keywords: Paperboard; Ultrasonic vibrations; Deep-drawing; Cardboard

Contact information: Chair of Processing Machines and Processing Technology, Technische Universität Dresden, Bergstraße 120, 01069 Dresden, Germany;

*Corresponding author: albrecht.loewe@tu-dresden.de

\section{INTRODUCTION}

The forming of cardboard is a key technology for producing sustainable packaging solutions based on recyclable fiber materials. To produce three-dimensional packages, the only currently available processes are folding, bending, and wrapping in combination with separate gluing steps. These processes only allow a small variety of geometric designs for packaging and therefore hinder the further spread of cardboard as a packaging material. The production technology of deep-drawing has the potential to overcome such limitations. In the last decade, numerous research projects (Hauptmann 2010, 2017; Wallmeier 2014) have resulted in significant improvements in the format variety and quality of the formed parts. While the research into deep-drawing of cardboard has concentrated on rigid, heated tools in the past, ultrasonic tools have also been investigated in recent publications (Löwe et al. 2016). They are characterized by a higher energy focus with shorter processing times, increased material compaction, and a change in the drying and binding mechanisms. The purpose of this publication is to further contribute to the research in the field of deepdrawing of cardboard with vibrating tools.

Deep-drawing of cardboard exhibits some similarities to the classic deep-drawing as it is known from the forming of metallic materials (Fig. 1). A cardboard blank is placed between the die and the blank holder, which presses on the blank and the die with the blank holder force. After reaching this force, the punch moves though the die and pulls the blank with it. Two characteristic phenomena are the wrinkle formation and the wrinkle 
compaction. In the part of the blank that is later formed into the cup wall, wrinkles will occur because of the excess material. By compressing the material in the sheet plane, the density of the cup wall is increased and as soon as the compressibility in-plane is exhausted, the excess material moves out of the sheet plane. This is shown in Fig. 1, in which a circular ring sector $\left(\mathrm{CRS}_{1}\right)$ merges into the circular ring sector $\mathrm{CRS}_{2}$. The compression becomes visible based on the lengths of the bounding circular arcs (Hauptmann et al. 2015). Immediately after entering the drawing gap between the die and the punch, the wrinkled material is compacted and compressed to the width of the gap. The compacted excess material forms a firm wall, which gives mechanical and dimensional stability to the cup.

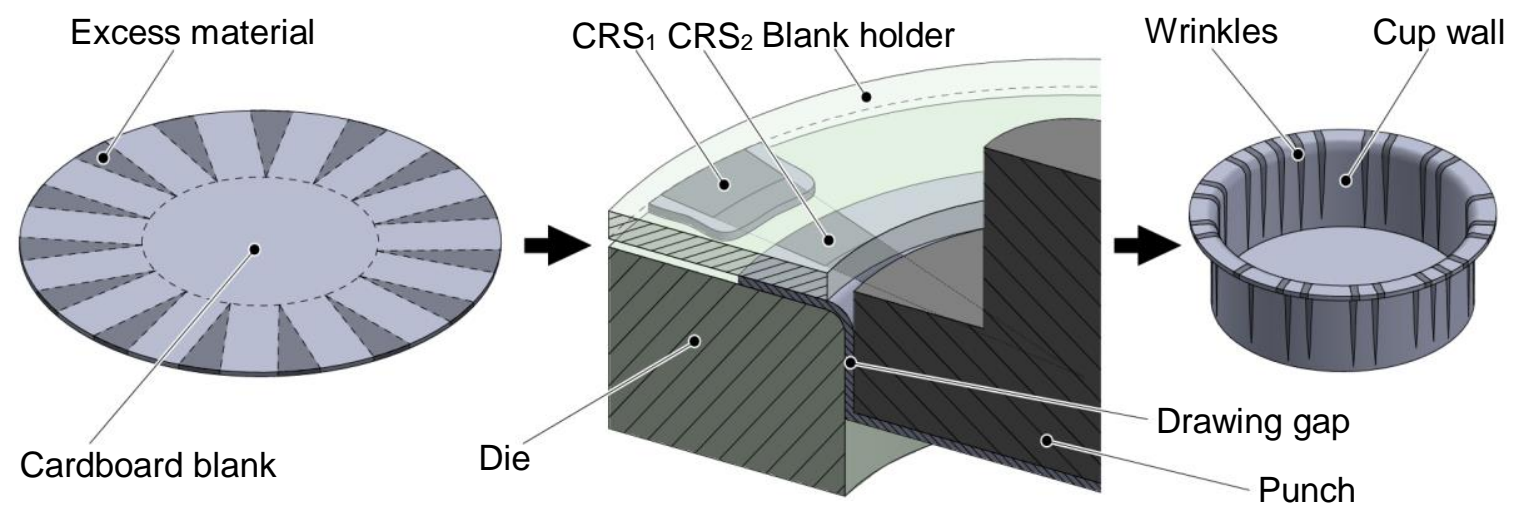

Fig. 1. Definition of terms and explanation of the deep-drawing process

In the past, all deep-drawing tools were heated, which made it possible to remove moisture from the material and improve the formability of cardboard. In contrast, in a paper by Löwe et al. (2016), a deep-drawing machine with unheated ultrasonic tools was presented. The die and the punch vibrate in a longitudinal oscillation mode with $20 \mathrm{kHz}$. The authors investigated the effects and application limits of the ultrasonic tools and came to the conclusion that a well suited sonotrode must meet numerous requirements for the process and the formed parts. On the one hand, it must heat the cardboard uniformly and precisely during the process to improve formability, and on the other hand the formed parts must have a firm cup wall and low shape deviation and surface roughness (Löwe et al. 2017).

Therefore, the functional design of future tool sonotrodes raises the question of which vibration mode in the tools best meets these requirements. Because the production of sonotrodes is complex and expensive, a new sonotrode cannot be produced for every vibration mode to be studied. Therefore, the authors have investigated the heating of cardboard in contact with ultrasonic surfaces with substitute experiments (Löwe et al. 2019). They used vibrations whose vibration vectors (Fig. 2) were orientated perpendicularly and parallel to the cardboard surface and came to the conclusion that a vibration directed perpendicularly to the cardboard surface heats up the material more uniformly and is therefore the best suited. To heat up the cardboard, a future deep-drawing sonotrode should vibrate in such a way that the vibration vector hits the material perpendicularly at all points of contact. On the basis of the approach by Löwe et al. (2019), the effects of the process parameters (vibration direction and amplitude, contact pressure) on the properties of formed parts shall be investigated in this publication. Together with the previous investigations, a functional design of deep-drawing sonotrodes becomes possible. 
The influence of process parameters on the properties of ultrasound-assisted deepdrawn cups has already been studied (Löwe et al. 2017). However, the experiments were conducted with a single die sonotrode with a variable vibration vector over its surface so that an exact determination of the influence of the angle of the vibration vector was not possible (Löwe et al. 2016; Hauptmann 2017).

The smoothing effect of ultrasonic vibrations on cardboard was investigated, but the experiments were conducted only on non-wrinkled paper and can therefore not be directly transferred to a wrinkled cup wall. The sonotrode was a vibrating roll, which also does not allow a conclusion about the effect of the angle of vibration (Wanske 2010). Furthermore, there are numerous publications on the smoothing of metals with vertical and parallel oscillation (Bozdana and Gindy 2005; Bai and Ming 2014; Hu and Shimizua 2018), but not on the smoothing of cardboard.

\section{EXPERIMENTAL}

\section{Materials}

To produce the test material for the substitute experiments, cups according to Fig. 2 were manufactured, and rectangular pieces were extracted so that the wrinkle direction in the pressure area pointed in the machine direction (MD) of the material. The number of wrinkles in the pressure area was random, but normally distributed with a small standard deviation $(\mu=5.8, \sigma=0.5)$. The orientation of the wrinkles was radially oriented, but due to the small dimensions of the pressure area they were assumed to be sufficiently parallel and the load therefore sufficiently orthogonal to the direction of the wrinkles. The test material can be inserted in the experimental setup presented in Fig. 3 (Löwe et al. 2019). It was designed to be installed in a compression testing machine (RetroLine Z020; ZwickRoell, Ulm, Germany) with which a pressure of up to $20 \mathrm{MPa}$ can be applied on an area of $1 \mathrm{~cm} \times 1 \mathrm{~cm}$ of the test material so that the pressure acting in the drawing gap can be simulated.

a)

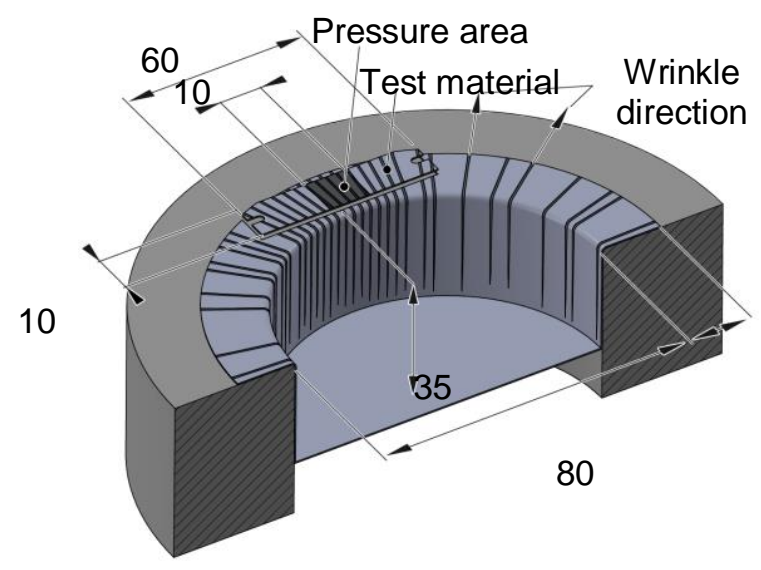

b)

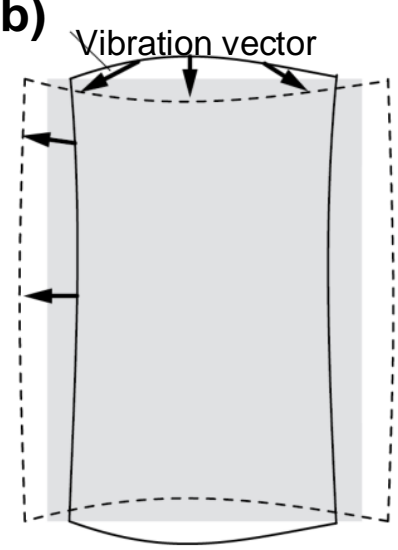

Fig. 2. a) Production of the test material and definition of the wrinkle direction (deep-drawing parameters: material $=$ Trayforma natura 350 , material moisture $=6.1 \%$, blank holder force $=2$ $\mathrm{kN}$, heated tools (i.e., no ultrasound): die temperature $=140^{\circ} \mathrm{C}$, punch temperature $=80^{\circ} \mathrm{C}$ ); b) Definition of the vibration vector; the end positions of the vibration mode (solid and dashed black lines) of an object (gray) are depicted together with the vibration vector of several points on the surface (black arrows) 


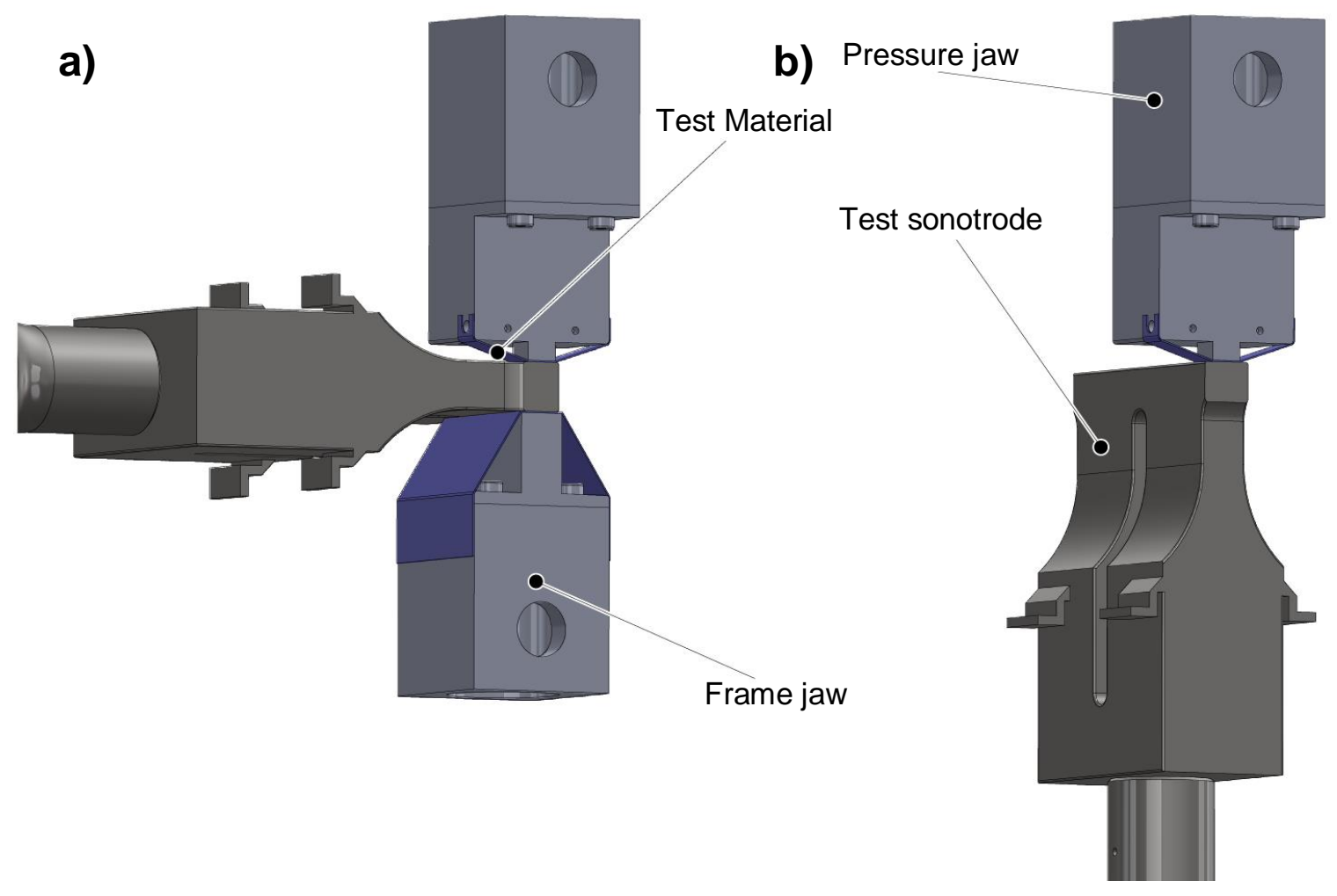

Fig. 3. Sketch of the setup for applying pressure and vibration on the test material: the vibration vector was orientated a) parallel and b) perpendicular to the material surface (sample holder not shown for sake of clarity)

The time to apply the pressure was set low at $1 \mathrm{~s}$ to minimize falsification from the relaxation of the cardboard. The position that the pressure testing machine reached to set the pressure was maintained for the duration of the experiment. The initial pressure was increased non-linearly during the experiments to achieve a higher resolution in the lower pressure range. The oscillation time was equal to the contact pressure time. The parts of the sonotrode surface with which the material comes into contact vibrate with sufficient accuracy in parallel or perpendicular direction to the material surface and are polished to a roughness value of $0.2 \mu \mathrm{m}$ to $0.4 \mu \mathrm{m}$ (Löwe et al. 2019).

Typical industrial cardboard for tray forming was used in the experiments (Trayforma natura (TF); STORA ENSO, Stockholm, Sweden). It is a three-layered material of virgin-quality fiber made of sulphate pulp and chemithermomechanical pulp (CTMP) in the middle and sulphate pulp in the outside layers. The grammage and thickness were $350 \mathrm{~g} / \mathrm{m}^{2}$ and $460 \mu \mathrm{m}$, respectively. The moisture content under standard climate conditions in the laboratory $\left(23{ }^{\circ} \mathrm{C}\right.$ and $50 \%$ relative humidity) was $6.1 \% \pm 0.3 \%$ in accordance with DIN EN ISO 287 (2009). The surface roughness of the material was 400 $\mathrm{mL} / \mathrm{min}$ (top) and $500 \mathrm{~mL} / \mathrm{min}$ (reverse) according to the Bendtsen air leakage method as per ISO 8791-2:2013-09 (2013).

The complete experimental design is shown in Table 1. Five measurements were performed for each test point and summarized in a box plot. 
Table 1. Experimental Design for the Measurement of the Cup Parameters

\begin{tabular}{|c|c|}
\hline Parameter & Level \\
\hline Material & TF350 \\
\hline Pressure $(\mathrm{MPa})$ & $0.5 / 1.5 / 2.5 / 3.5 / 5 / 7.5 / 10$ \\
\hline Initial Material Moisture $(\%)$ & 6.1 \\
\hline Vibration Mode & Parallel / Perpendicular \\
\hline Amplitude $(\mu \mathrm{m})$ & $10 / 20$ \\
\hline Oscillation Time $(\mathrm{s})$ & 1.0 \\
\hline
\end{tabular}

The stability of the test material was determined by a strip tensile test according to ISO 13934-1:2013-08 (2013), which was presented in Hauptmann and Majschak's 2016 study. It was assumed that the stability of the cup wall depended mainly on the ability of the wrinkles to withstand tensile forces perpendicular to their wrinkle direction. As a measure of the stability, the gradient at the beginning of the force-deformation curve was taken. It is plotted relative to the gradient of the untreated test material and is a measure of the increase in strength of the wrinkles that have been ultrasonically treated compared to the untreated cup wall.

The measurement of surface roughness was completed according to the method presented in (Löwe et al. 2017). The only difference was that the measurement object was not a round cup but the flat test material. The surface roughness of the cup wall was defined as the $R_{\text {a }}$ value (mean absolute deviation from the global mean) of the surface profile. It was scanned five times and the mean surface profile was calculated from these five scans to minimize the measurement noise. Fluctuations in the signal due to unavoidable geometrical inaccuracies of the measurement setup were eliminated with the Fourier analysis (explained in detail in Löwe et al. (2017)).

The shape deviation can only be measured on finished cups and therefore cannot be determined from the substitute tests. However, previous experiments (Löwe et al. 2017) show a clear correlation of the shape deviation with the stability, so the shape deviation can be determined with statistical certainty (Fig. 4).

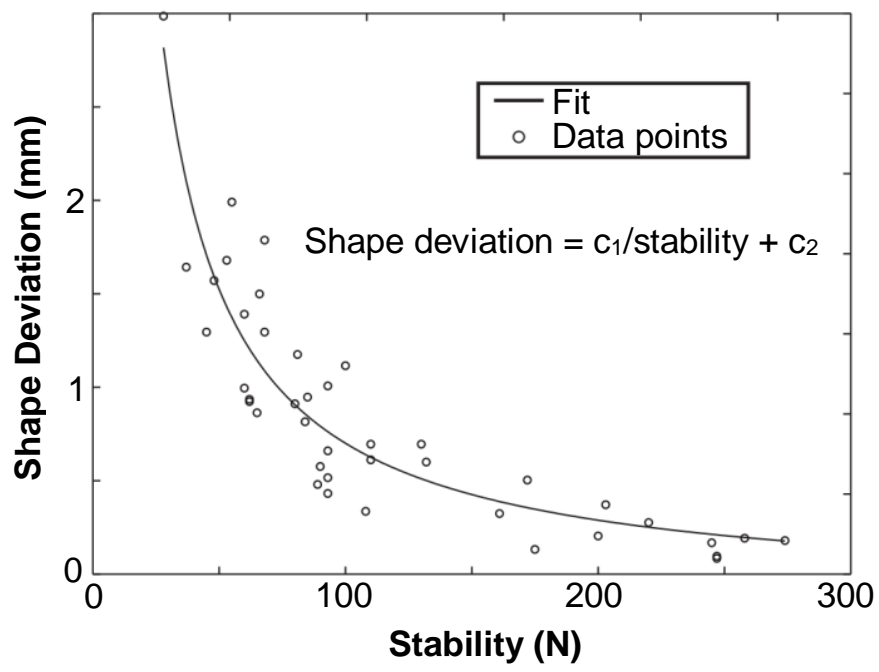

Fig. 4. Plot of the shape deviation as a function of the stability of the cups tested by Löwe et al. (2017); Fit: $\mathrm{c}_{1}=68.67 \mathrm{Nmm}, \mathrm{c}_{2}=0.40 \mathrm{~mm}$, and $\mathrm{R}^{2}{ }_{\mathrm{adj}}=0.818$ 
The scanning electron microscopy (SEM) images were taken with a JSM 6510, the therefore needed sputter coating that was completed with a JFC 1200 Fine Coater, both from Jeol Ltd., Tokyo, Japan.

The data evaluation was done in MATLAB (TheMathWorks, Natick, MA, USA).

\section{RESULTS AND DISCUSSION}

\section{Wrinkle Strength}

The tests showed that the strength of the wrinkles rose with increasing contact pressure (Fig. 5). The reason for this was assumed to be the decrease in porosity, which led to more contact area and possible new bonds and mechanical entanglements between the fibers and at the touching surfaces in wrinkle areas. SEM images of the cross-section (Fig. 6) support this hypothesis.

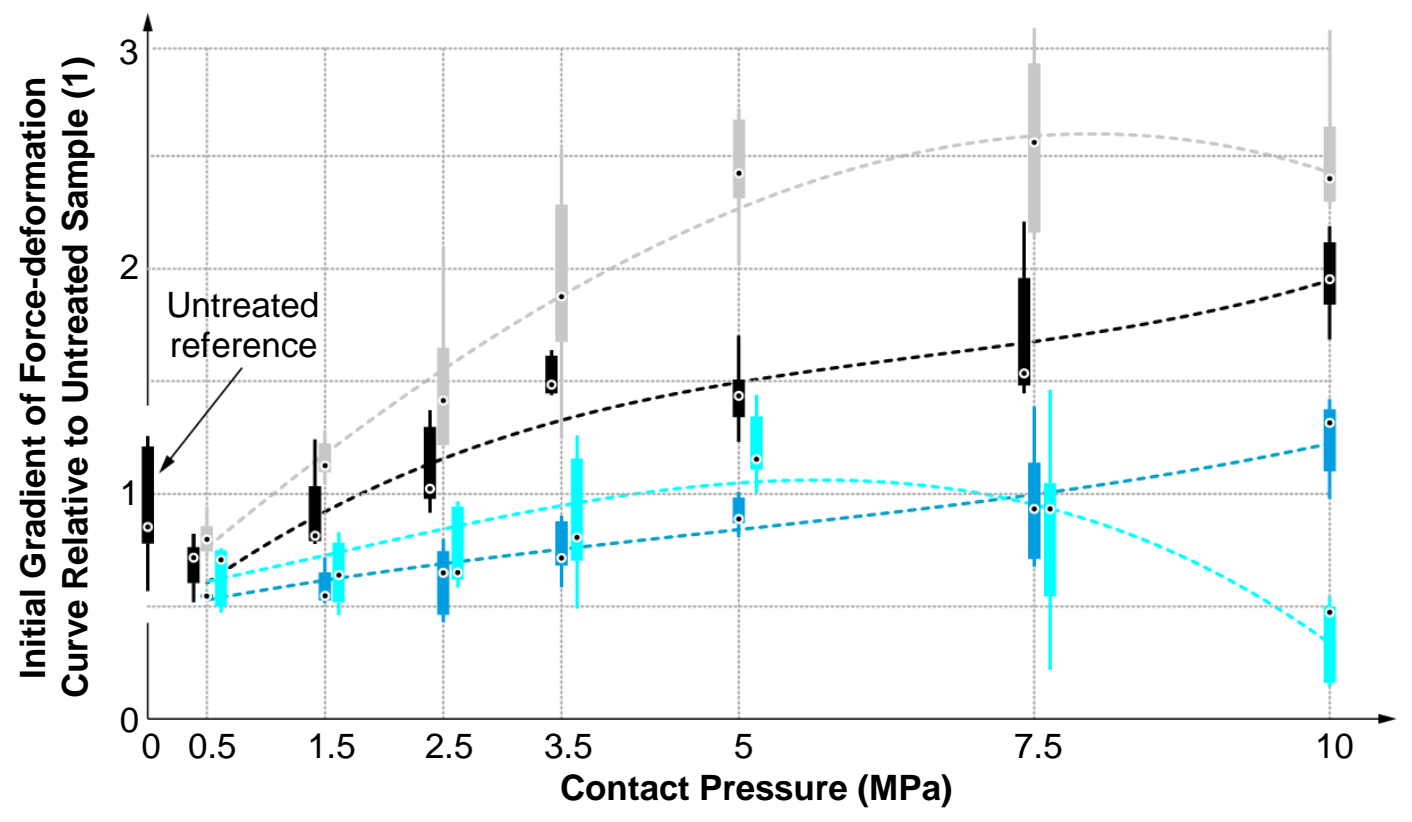

$$
\begin{aligned}
& \text {..P Perpendicular / } 10 \mu \mathrm{m}\left(\mathrm{R}^{2}{ } \text { adj }=0.81\right) \ldots \text { Parallel } / 10 \mu \mathrm{m}\left(\mathrm{R}^{2}{ }^{2} \text { dj }=0.69\right) \\
& \ldots \text { Perpendicular } / 20 \mu \mathrm{m}\left(R^{2} \text { adj }=0.80\right) \cdots \text { Parallel } / 20 \mu m\left(R^{2} \text { adj }=0.42\right)
\end{aligned}
$$

Fig. 5. Plot of the relative initial force-deformation gradient as a function of the contact pressure, the ultrasonic amplitude, and the direction of vibration (perpendicular/parallel). The measurement data was fitted with a $3^{\text {rd }}$-order polynomial (adjusted $R^{2}$-value given in the legend). Measurement data is plotted as barplots (recorded at the pressures given on the x-axis, but slightly moved sideways to avoid overlap).

The highest wrinkle strength was reached with the vertical vibration of $20 \mu \mathrm{m}$ amplitude and more than doubled compared to the reference sample. However, a pressure above $5 \mathrm{MPa}$ did not lead to a further increase in wrinkle strength as the highest achievable density was already reached and the cardboard strip only began to decompose at higher pressures due to the stronger heat development. At low pressures below 1.5 MPa, the wrinkle strength was lower than that of the untreated sample, which is explained in Fig. 7. When a wrinkled test sample (Fig. 7a) was subjected to a pressure in z-direction (Fig. 7b), fibre bonds and mechanical entanglements inside of the material and between touching 
surface areas were destroyed. This led to reduced tensile strength in the x-direction. This effect was compensated at higher pressures by the creation of new bonds.
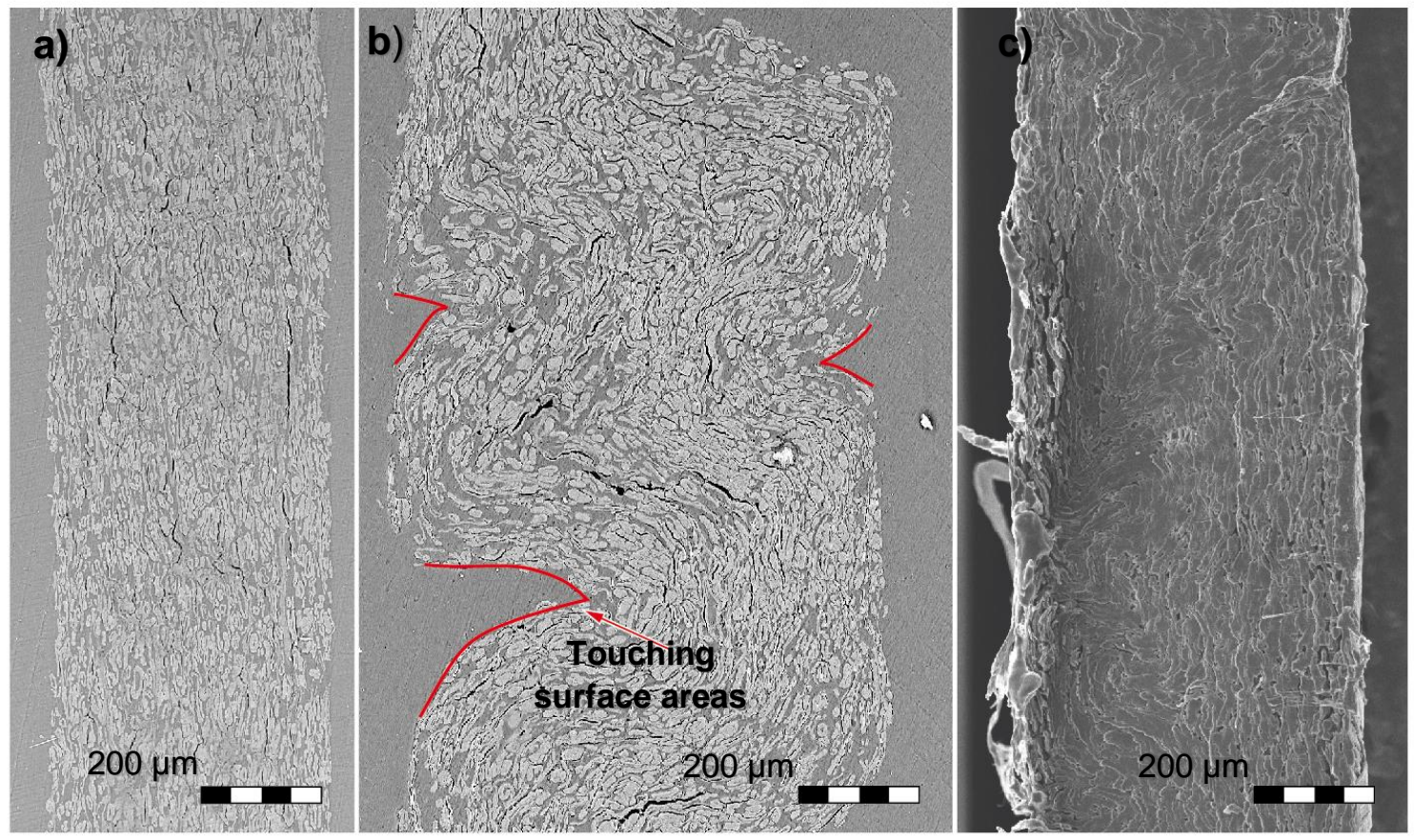

Fig. 6. SEM images of the cross-section of the cup wall: a) undeformed raw material (TF 350), b) deep-drawn without ultrasonic support, and c) deep-drawn with ultrasonic support

a)

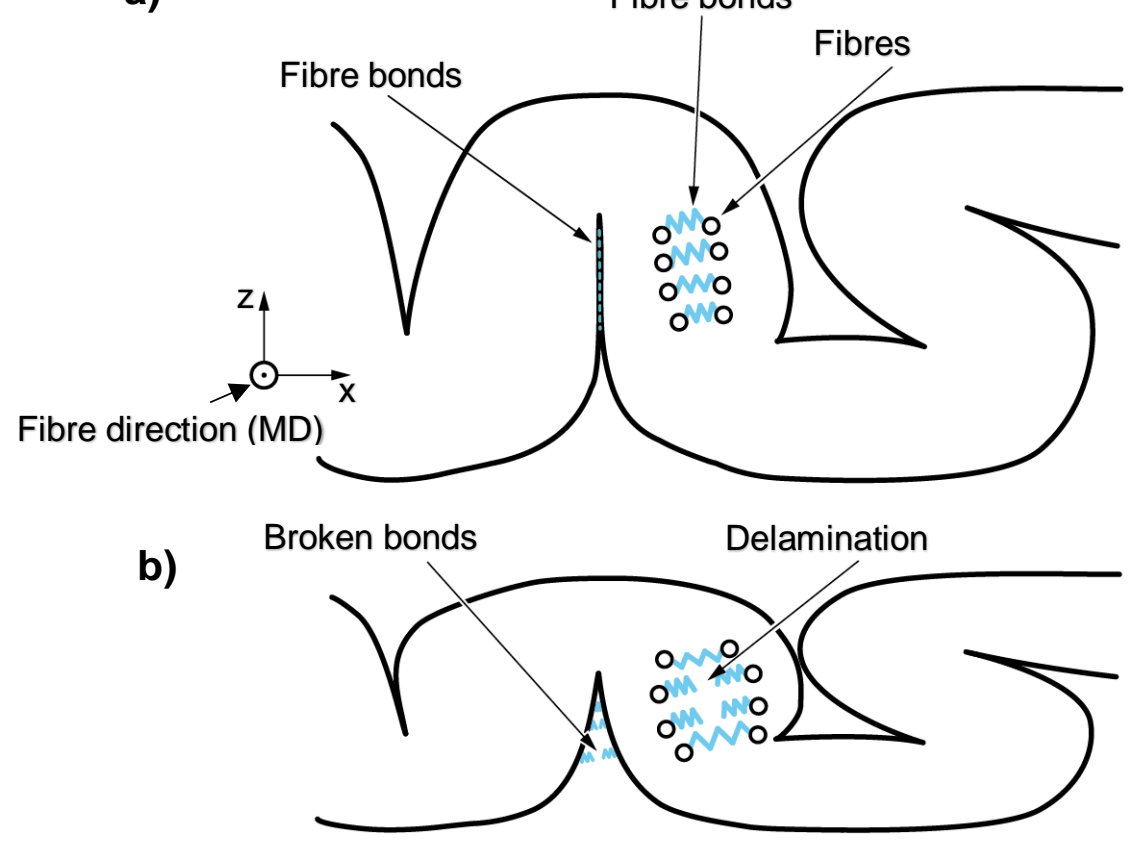

Fig. 7. Sectional view of a test sample: a) untreated reference sample and b) test sample flattened in z-direction 
The amplitude should not exceed $10 \mu \mathrm{m}$ with parallel vibration, because the material started to decompose at a contact pressure of $5 \mathrm{MPa}$ upwards and completely lost its wrinkle strength. However, even at an amplitude of $10 \mu \mathrm{m}$, comparatively high pressures were needed to reach the wrinkle strength of the reference sample again. The compression of the cardboard was caused only by the static contact pressure and not by the vibration itself. Therefore, the closing of the pores required a higher pressure than with vertical vibration. Another reason could have been the damage to the fibers and fiber bonds caused by the induced high-frequency shear stresses.

\section{Surface Roughness}

Scanning electron microscopy images of the ultrasonically treated cardboard sample (Fig. 8) showed a surface on which most protruding areas were levelled. While the individual fibers were still distinguishable at $0 \mu \mathrm{m}$ and $10 \mu \mathrm{m}$ amplitude, they formed a homogeneous surface at $20 \mu \mathrm{m}$ amplitude. The width of the wrinkles ranged from approximately $50 \mu \mathrm{m}$ (no ultrasound) to $25 \mu \mathrm{m}$ (20 $\mu \mathrm{m}$ amplitude).
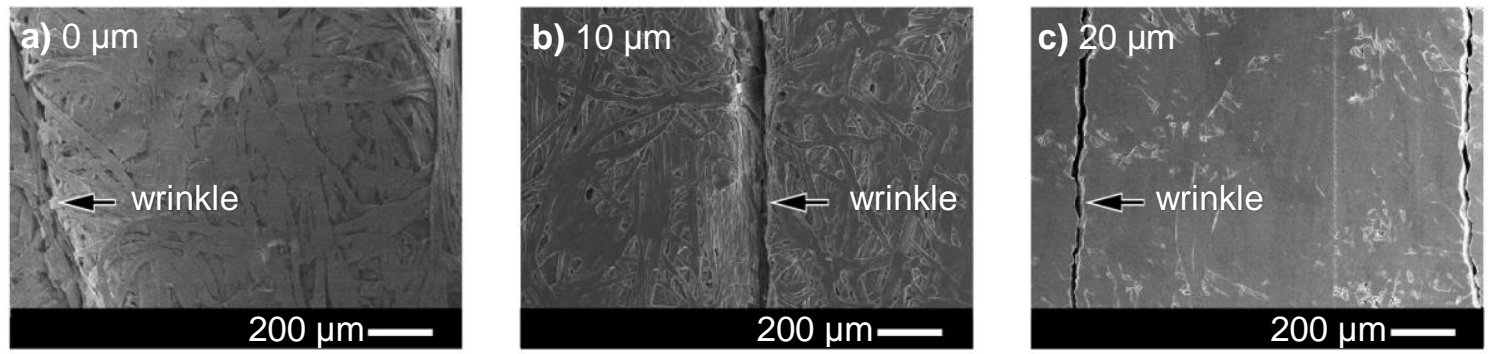

Fig. 8. SEM images of the surface of the cup wall after deep-drawing with various amplitudes

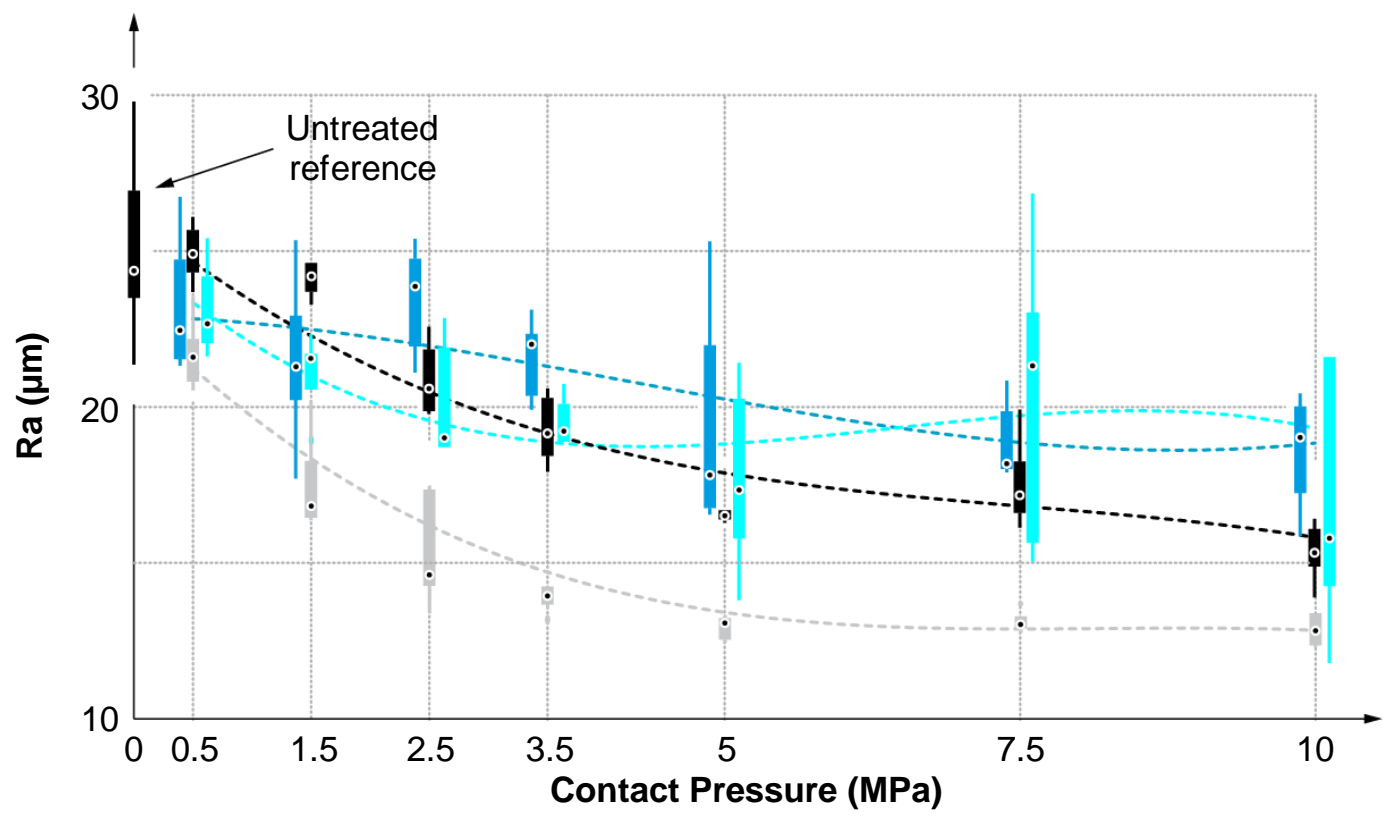

œ. Perpendicular / $10 \mu \mathrm{m}\left(\mathrm{R}^{2}\right.$ adj $\left.=0.75\right) \cdots$ Parallel / $10 \mu \mathrm{m}\left(\mathrm{R}^{2} \mathrm{adj}=0.33\right)$

$\ldots$ Perpendicular $/ 20 \mu \mathrm{m}\left(\mathrm{R}^{2}\right.$ adj $\left.=0.87\right) \cdots$ Parallel $/ 20 \mu \mathrm{m}\left(\mathrm{R}^{2}\right.$ adj $\left.=0.04\right)$

Fig. 9. Plot of the surface roughness as a function of the contact pressure, the ultrasonic amplitude, and the direction of vibration 
Figure 9 shows the $R_{\mathrm{a}}$ value as a function of the process parameters. It was concluded from the experiments that the vertical vibration was better suited to reduce the surface roughness. With this direction of vibration, the minimum $R_{\mathrm{a}}$ value was reached at a contact pressure of approximately $3.5 \mathrm{MPa}$. Because all protruding areas were already levelled, a further increase in pressure no longer led to a decrease in roughness, but only to excessive heating and decomposition of the cardboard. The roughness converged towards a lower limit of approximately $12 \mu \mathrm{m}$.

With the parallel oscillation direction and $10 \mu \mathrm{m}$ amplitude, the surface roughness only decreased when the contact pressure exceeded approximately $5 \mathrm{MPa}$. There was not yet enough pressure below this threshold because it was only applied by the compression testing machine. There was no contribution by the periodic compression as with the vertical direction of oscillation. Another reason could have been the roughening of the surface caused by the relative movement. At the final pressure of $10 \mathrm{MPa}$, the roughness was approximately $170 \%$ higher than with the vertical direction of vibration. With an amplitude of $20 \mu \mathrm{m}$ the cardboard started to decompose at a contact pressure of approximately $5 \mathrm{MPa}$. This made the surface brittle and no longer reflected the confocal laser beam reliably, which increased the standard deviation. For wrinkle strength, the pressure for an acceptable result was approximately the same as for the surface roughness. This was an advantage because the optimum of both values was achieved without applying too much pressure and the risk of decomposition remained low.

\section{CONCLUSIONS}

1. A vibration mode, whose direction vector hits the material perpendicularly on the entire surface, will produce the best cup properties. This is because, in addition to static compression, it generates a cyclic compression that is in the order of magnitude of an oscillation amplitude. The parallel vibration does not show this cyclic compression, which means that more contact pressure is required to produce effects comparable to those when using perpendicular vibration, which increases the risk of decomposition.

2. The strength of the wrinkles in the cup wall against a vertical tensile force rose with increasing contact pressure on the sonotrode. Depending on the amplitude and the vibration mode, there is an upper pressure limit above which the wrinkle strength stagnates or even decreases due to excessive heating and decomposition of the material.

3. There was a pressure threshold, below which the wrinkle strength was below that of the untreated reference sample. This was due to broken fibre bonds and mechanical entanglements between touching parts of the surface area and delamination inside of the material. This effect was compensated for by the formation of new bonds in the higher pressure range.

4. The vertical vibration reached the minimum $R_{\mathrm{a}}$ value at a contact pressure of approximately 3.5 MPa. A further increase in pressure no longer led to a decrease in roughness, but only to excessive heating and decomposition of the cardboard. The roughness converged towards a lower limit of approximately $12 \mu \mathrm{m}$. 


\section{ACKNOWLEDGEMENTS}

The authors acknowledge support by the German Research Foundation and the Open Access Publication Funds of the TU Dresden. They also thank the Papiertechnische Stiftung Heidenau (PTS) for the SEM images.

\section{REFERENCES CITED}

Bai, Y., and Ming, Y. (2014). "Optimization of metal foils surface finishing using vibration-assisted micro-forging," Journal of Materials Processing Technology 214(1), 21-28. DOI: 10.1016/j.jmatprotec.2013.07.011

Bozdana, A. T., and Gindy, N. N. Z. (2005). "Deep cold rolling with ultrasonic vibrations - A new mechanical surface enhancement technique," International Journal of Machine Tools Manufacture 45(6), 713-718. DOI: 10.1016/j.ijmachtools.2004.09.017

DIN EN ISO 287 (2009). "Paper and board - Determination of moisture content of a lot Oven-drying method (ISO 287:2009); German version EN ISO 287:2009

Hauptmann, M. (2010). Die Gezielte Prozessführung und Möglichkeiten zur Prozessüberwachung beim Mehrdimensionalen Umformen von Karton durch Ziehen [The Specific Process Management and Possibilities for Process Monitoring in the Multi-dimensional Forming of Cardboard by Deep-drawing], Ph.D. Dissertation, Technische Universitat Dresden, Dresden, Germany.

Hauptmann, M. (2017). Neue Einsatzpotentiale Naturfaserbasierter Materialien in der Konsumgüterproduktion durch die Technologische Entwicklung des Ziehverfahrens am Beispiel der Verpackung [New Application Potential of Natural Fiber Based Materials in the Consumer Goods Production Through Technological Development of the Deep-drawing Process Using the Example of Packaging], Postdoctoral Thesis, Technische Universitat Dresden, Dresden, Germany.

Hauptmann, M., and Majschak, J.-P. (2016). "Characterization of influences on the wall stability of deep-drawn paperboard shapes," BioResources 11(10), 2640-2654. DOI: 10.15376/biores.11.10.2640-2654

Hauptmann, M., Wallmeier, M., Erhard, K., Zelm, R., and Majschak, J.-P. (2015). “The role of material composition, fiber properties and deformation mechanisms in the deep drawing of paperboard," Cellulose 22(5), 3377-3395. DOI: 10.1007/s10570015-0732-X

Hu, J., and Shimizua, T. (2018). "Ultrasonic dynamic impact effect on deformation of aluminum during micro-compression tests," Journal of Materials Processing Technology 258, 144-154. DOI: 10.1016/j.jmatprotec.2018.03.021

ISO 8791-2:2013-09 (2013). "Paper and board - Determination of roughness/smoothness (Air leak methods) - Part 2: Bendtsen method," International Organization for Standardization, Geneva, Switzerland.

ISO 13934-1:2013-08 (2013). “Textiles - Tensile properties of fabrics - Part 1:

Determination of maximum force and elongation at maximum force using the strip method," International Organization for Standardization, Geneva, Switzerland.

Löwe, A., Hofmann, A., and Hauptmann, M. (2016). "The use and application of ultrasonic vibrations in the 3D deformation of paper and cardboard," Journal of Materials Processing Technology 240, 23-42. DOI: 10.1016/j.jmatprotec.2016.09.006 
Löwe, A., Hauptmann, M., and Majschak, J.-P. (2017). "The effect of ultrasonic oscillation on the quality of 3D shapes during deep-drawing of paperboard," BioResources 12(4), 7178-7194. DOI: 10.15376/biores.12.4.7178-7194

Löwe, A., Hauptmann, M., Hofmann, A., and Majschak, J.-P. (2019). “Temperature development of cardboard in contact with high-frequency vibrating metal surfaces," BioResources 12(4), 3975-3990. DOI: 10.15376/biores.12.4.3975-3990

Wallmeier, M. (2014). "New methods for quality analysis of deep-drawn packaging components from paperboard," Packaging Technology and Science 28(2), 91-100. DOI: $10.1002 /$ pts.2091

Wanske, M. (2010). Hochleistungs-ultraschallanwendung in der Papierindustrie Methoden zur Volumenschonenden Glättung von Oberflächen [High-perforamnce Ultrasonic Application in the Paper Industry - Methods for Volume-saving Smoothing of Surfaces], Ph.D. Disseration, Technische Universitat Dresden, Dresden, Germany.

Article submitted: December 20, 2019; Peer review completed and article accepted: February 22, 2020; Published: March 2, 2020.

DOI: $10.15376 /$ biores.15.2.2763-2773 